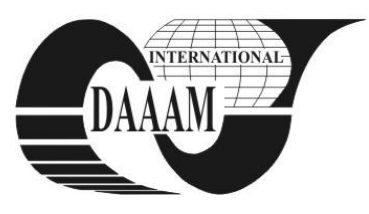

Annals of DAAAM for 2012 \& Proceedings of the 23rd International DAAAM Symposium, Volume 23, No.1, ISSN 2304-1382 ISBN 978-3-901509-91-9, CDROM version, Ed. B. Katalinic, Published by DAAAM International, Vienna, Austria, EU, 2012 Make Harmony between Technology and Nature, and Your Mind will Fly Free as a Bird

\title{
THE MISSING LINK - KNOWLEDGE CREATION AND INNOVATION
}

\author{
TEKIC, Z[eljko]; COSIC, I[lija] \& KATALINIC, B[ranko]
}

\begin{abstract}
This paper tackles the question: What determines the direction and intensity of the innovation activities from the perspective of knowledge? It addresses research on a chronology of knowledge and innovation development in the remote communication in order to obtain a fuller and richer understanding of knowledge - innovation cycles. The results show that knowledge always tends to develop towards the idea of the ideal, while the direction of development of knowledge is determined by the difference between what is needed and what is currently possible. The intensity of converting knowledge into innovation is defined by the limitations arising from the condition of society (profitability, legality, ethics) and compliance with nature (sustainability).

Keywords: knowledge, innovation, idea of the ideal, conditions
\end{abstract}

\section{INTRODUCTION}

Knowledge is understood to be the key component of all forms of innovation. However, while different knowledge processes have a beneficial impact on innovation, it has been recently shown that the knowledge creation impacts innovation the most and fully mediates the impact of other knowledge processes (intra-organizational knowledge sharing, external knowledge acquisition and documentation) on innovation performance [1]. Therefore, understanding the link between knowledge creation and innovation becomes crucial for better understanding how competitive advantage is created and sustained at the beginning of the $21^{\text {st }}$ century. The purpose of this paper is to contribute to this goal by providing insight into the knowledge innovation interface. To this end, the research looks at the knowledge development and related innovations in the remote communication over time. In this case historiography has been considered to be a useful approach because there is a high possibility that the current situation is a part of a development cycle and that understanding the nature of the cycle could provide some insights into the current situation [2]. The remainder of the paper is structured as follows: a brief literature review on the subject of knowledge and innovation is followed by research questions and an explanation of the research methodology. The paper then presents results, describes the model and its main characteristics followed by preliminary conclusions and implications.

\section{LITERATURE REVIEW}

When approached from the knowledge-based perspective, innovation can be defined as generation and exploitation of new forms of knowledge [3] or as the problem-solving process in which organizations manipulate knowledge to create new products [4]. Knowledge creation and innovation are thus often seen in the literature as two sides of the same coin. However, in this particular paper the authors make a subtle difference between the processes of knowledge creation and innovation, using the term knowledge creation to identify the process of developing the new knowledge, and the term innovation - to refer to the results of the successful application of this new knowledge.

Although knowledge is essential to innovation, exposure to a problem is generally considered to be the initiator of the innovation process [5]. These initial problems are mainly sourced from outside of the organizations [6] and are almost exclusively viewed through the prism of technology and market [7] and [8]. Namely, a number of authors have combined technological and market perspectives to develop theoretical models of innovation, based on the qualitative and quantitative differences introduced by an innovation compared to the existing technology and market [7], [9] and [10]. The differences arise only in the way how these two elements (technology push and market pull) are interrelated [8]. Recently the notion of eco or green innovation has emerged. It is based on the need for sustainable development - the ability of current generations to meet their own needs without compromising the opportunities of future generations to meet theirs.

The aim of green innovations is to provide value to users and businesses, but also to significantly reduce the impact on the environment and to contribute to balancing financial, social and environmental performance. Similarly, the influences of culture and adopted thought patterns are important for innovation. Although globalisation increases the mobility of goods, services, labour, technology and capital throughout the world, making various differences smaller, national cultural values seem to be less influenced by these tremendous changes [11]. Consequently, the success of new products and other innovations depends on the consideration of customers' and users' cultural values in development processes. Thus, it is clear that innovations should be viewed from a broader perspective than technology / market framework. On the other hand, the most influential model of knowledge creation developed by [5], views knowledge creation as the interaction between tacit and explicit knowledge which is amplified through the four modes of knowledge conversion. The movement through the four modes of knowledge conversion forms a spiral that becomes larger in scale as it moves up through the ontological levels [5].

However, it is not clear what the axis around which spiral cycles of knowledge improvement have been 
implemented is. The research question we ask in this paper is: What determines the direction and intensity of the innovation activities from the perspective of knowledge?

\section{METHODOLOGY}

Knowledge and innovations, as well as their management, emerge during a period of time as technologies, societies and organizations evolve in response to various internal and external forces. Therefore, the knowledge - innovation interface can be studied using evidence of past events and decisions. Although not a common method of research in industrial engineering and management, there are some very important history and chronology-based research papers [12] and [13] in which researchers looked at specific cases over a long period of time in order to gain a deeper and fuller understanding of a cycle, situation or a series of circumstances [2]. Following the same logic, our research focuses on a chronology of knowledge and innovation development in the remote communication in order to obtain a fuller and richer understanding of knowledge - innovation links.

\section{IDEA OF AN IDEAL}

The development of remote communication has been going on for the past several thousands of years and went through several phases. In the first phase, people used the smoke signals and fire to communicate between distant locations. This way of communication enabled the transfer of a limited set of discrete messages. Then, in the later phases, the message complexity increased, enabling real-time communication without mediators and using more senses. Today, there are no obvious restrictions in remote communication. By looking at development of the remote communication over time, it can be observed that the guiding principle was to make the remote communication as similar to face-to-face communication as possible. This means that remote communication should enable natural and confidential exchange of information in real time, include more senses, not require much effort and expenditure, be simple, and allow mobility. The described remote communication is desirable, but hardly achievable in all of the elements mentioned (for example, today communication confidentiality is a hot topic). It represents the idea of an ideal remote communication. In order to provide arguments for this hypothesis, Table 1 summarizes the most important steps and how they contributed to the achievement of ideal remote communication.

As indicated by the analysis presented, common to the development of all the listed forms of remote communication is that they represent stages in the development of an ideal remote communication. That means the idea of remote communication is the vertical line along which the cycles of communication improvement are implemented. This is not something specific to development of remote communication. When looking around, we notice that in every area of human activity, an idea of the ideal, which leads and directs the development of knowledge in the given area, can be identified. For example, the idea of an ideal transport can be traced as a tendency towards transporting people and goods from point $\mathrm{A}$ to point $\mathrm{B}$ in a faster, safer and cheaper manner. The development of this idea can be traced from the primitive use of animals, through the first carriages and ships, the occurrence of railways, the first car, overseas ship, to the development of air transport and space programmes. We have a similar situation with ideas of an ideal medical care, ideal of education, ideal material and so on.

Following this argumentation, the idea of the ideal can be defined as a hypothetical construct by which many of the perceptions of an object or phenomenon are summarized, abstracted and styled, in order to obtain a coherent and logical reflective totality. However, this conceptual or analytical model can be useful because it can serve for better understanding of the world around us.

\begin{tabular}{|c|c|c|}
\hline $\begin{array}{l}\text { Type of remote } \\
\text { communication }\end{array}$ & Features & $\begin{array}{l}\text { Approaching to ideal } \\
\text { communication }\end{array}$ \\
\hline Smoke signals, fire & $\begin{array}{l}\text { The first form of remote information transfer using simple signals, enables the } \\
\text { transmission of very short messages in real time, conditioned by weather } \\
\text { conditions, encrypted, and easily visible }\end{array}$ & $\begin{array}{l}\text { The first form of remote } \\
\text { communication, transmission of } \\
\text { discrete messages }\end{array}$ \\
\hline Letter, mail & $\begin{array}{l}\text { Remote information transfer in the form of a written text, enables the non- } \\
\text { real-time transmission of both long and short messages }\end{array}$ & $\begin{array}{l}\text { Transmission of complex } \\
\text { messages, information and } \\
\text { emotions }\end{array}$ \\
\hline Telegraph & $\begin{array}{l}\text { Remote transmission of text messages, with the messages transmitted } \\
\text { between two devices in the form of coded electrical signals, enables the real- } \\
\text { time transmission of both long and short messages, with the existence of } \\
\text { intermediaries (telegraphers) }\end{array}$ & Real-time transmission \\
\hline Telephone & $\begin{array}{l}\text { Remote voice transmission, with the messages transmitted between two } \\
\text { devices in the form of electrical signals, enables the real-time transmission of } \\
\text { messages of arbitrary length without mediator }\end{array}$ & $\begin{array}{l}\text { Real-time transmission without a } \\
\text { mediator }\end{array}$ \\
\hline Video telephone & $\begin{array}{l}\text { Transmission of both voice and images between the speakers, with the } \\
\text { messages between two devices transmitted in the form of electrical signals, } \\
\text { enables the real-time transmission of messages of arbitrary length, without } \\
\text { mediator }\end{array}$ & Inclusion of additional senses \\
\hline Mobile telephone & $\begin{array}{c}\text { Transmission of both voice and images while the speakers are still mobile, } \\
\text { messages between two devices are transmitted in the form of electrical } \\
\text { signals, enables the real-time transmission of messages of arbitrary length, } \\
\text { without mediator }\end{array}$ & $\begin{array}{l}\text { Mobility, } \\
\text { Available at all places in all times }\end{array}$ \\
\hline Internet & $\begin{array}{c}\text { Transmission of different types of data, enables the real time transmission of } \\
\text { multimedia messages of arbitrary length, messages are also available later, } \\
\text { without mediator }\end{array}$ & Low expenses, Multi medial \\
\hline Smart phone & $\begin{array}{l}\text { Integration, data and voice transmission, inclusion of several senses, } \\
\text { simplicity, multi media }\end{array}$ & Integration \\
\hline
\end{tabular}

Tab. 1. The analysis of the development of remote communication 


\section{CONDITIONS FOR THE EMERGENCE OF INNOVATIONS}

The conversion of knowledge into innovation must be discussed in the relation among systems of humans, artefacts, society and nature. The conditions and limitations that influence and shape this process arise from the interaction of the same systems. The system of humans sets a limit of what is the desired state, driven by the idea of living a more comfortable life and satisfying one's own needs. This system is dynamic; changes in what people believe, what they want and expect, how much they earn, create opportunities, as well as limitations. To meet their needs, people make artefacts from primitive tools and weapons to today's super computers, spacecrafts and artificial materials. All known technologies and existing products form the second important system in our consideration - the system of artefacts. This system provides a framework of what is (technically) feasible, what can be accomplished at the specific moment of time.

On the other hand, the system of society, personified in the market, legal norms, culture and public policy, determines the limits of what is permissible and profitable. This system is also far from being static. For example, by changing the law, a new option could be created or an existing one removed. Thus, for example, the deregulation of the telecommunications market has led to the emergence of a multitude of companies offering services of fixed and mobile telephony and internet providers. Although this system varies from country to country (due to differences in culture, legislation and political organization), these variations are now less under the influence of globalization.

The interaction between these three systems has long been a framework for understanding the development of innovations. However, satisfaction of human needs requires the consumption of limited resources that are either slowly- or non-renewable. In addition, abuse in the systems of artefacts (e.g. modern wars, nuclear energy, genetically modified food, etc.) and society (global economic crises) have put the system of people in a disadvantageous position. All this contributed to the growing need for maintaining the harmony between an individual and its environment, making this need one of the leading future forces. By the end of the twentieth century, the issue of sustainability of the planet became particularly relevant and inevitable in considerations regarding the development of innovations. The system of nature became the fourth element that affects the creation of knowledge and its conversion into innovations. This system leads to the type of development that meets the needs of the present, while not imperilling the ability of future generations to meet their own needs. It makes the exploitation of resources, direction of investments, orientation of technological development and institutional changes more balanced in order to to ensure the long-term survival and prosperity of human civilization.

Interaction of these four systems results in limitations as the intersection of sets of what humans need, what is technically feasible, what is profitable and permissible, and what is in harmony with nature. These limitations are not static, but shadow the dynamic of the systems which condition them - they are constantly changing, opening new opportunities for the application of knowledge and the emergence of innovation

\section{THE IDEA OF THE IDEAL, KNOWLEDGE AND INNOVATION}

Based on the above, it can be concluded that innovations occur as a result of materialization of knowledge under the existing conditions and limitations arising from the interaction of the system of people, society, artefacts and nature. This is graphically presented in Figure 1.

The relationship between what is currently possible and what humans need drives the materialization of knowledge. On the other hand, the conversion of the materialized knowledge into an innovation, i.e. its acceptance on the market and among people, depends on the limitations arising from the social conditions (culture, profitability, law) and the compliance with nature (sustainability). While these two factors are still not weighted equally at the emergence of innovation, they will inevitably become in the near future. Namely, the growing awareness of the need for environmental protection leads to higher environmental standards in the use of resources, thus providing a niche for the development of new industries (green energy, healthy food).

New ideas are sometimes accepted and scientifically grounded, but not technically feasible at the given moment. On the other hand, sometimes it is necessary to understand how to apply all that is possible for meeting people's needs. Both situations - when human needs are higher than what is technically feasible and when the level of technical capabilities exceeds the human needs are the drivers of innovation: in the first case, it is a technology push, in the second a market pull. For example, as today's speed of technology development exceeded the immediate needs of people (more than needed is possible) in many areas, people need to learn how to adapt the existing technology to the existing needs in order to get the maximum benefit from them [14].

\section{CONCLUSIONS}

This paper addressed the gap in understanding the link between knowledge creation and innovation. It refers to the question: What determines the direction and intensity of the innovation activities from the perspective of knowledge? In view of a wider perspective and the accompanying overall historical development of remote communication, it was shown that the guiding premise was the pursuit towards an ideal communication at a distance. Because in every sphere of life one idea of the ideal may be recognized, the final conclusion is that the idea of the ideal represents an abstract vertical axis around which cycles of knowledge improvement are implemented. The idea of the ideal represents a hypothetical construct which summarizes, abstracts and stylizes many observations on a specific object or phenomenon, so as to obtain a coherent and logical reflective whole. 


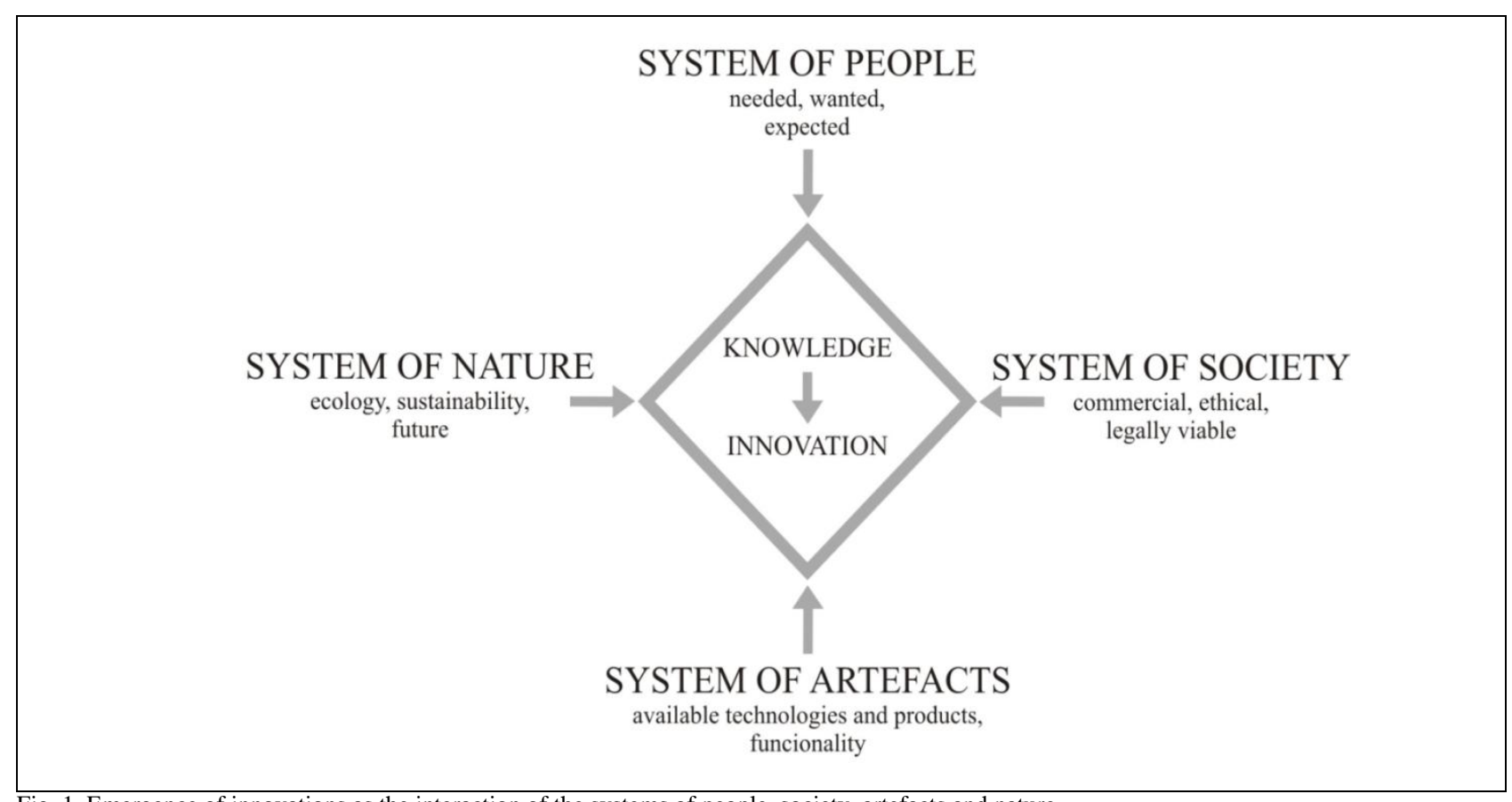

Fig. 1. Emergence of innovations as the interaction of the systems of people, society, artefacts and nature

The idea of the ideal is an abstract, utopian notion about a phenomenon that does not exist as such in reality, but only some of its attributes may be found.

Although a useful concept, the idea of an ideal was only the first step toward a more complete understanding of the link between knowledge creation and the occurrence of innovation. The next focus of research was the issue of conditions and restrictions under which the newly-formed (or existing) knowledge turns into innovation. Based on theoretical discussions, complete with examples, it was shown that restrictions and conditions stem from the interaction of four systems: humans, society, artefacts, and nature, as a cross section of sets of man's needs, those that are technically possible, that are profitable and permissible, and those that are in harmony with nature. These restrictions are not static, but shadow the dynamic of the systems which condition them - they are constantly changing, as they are, opening new opportunities for the application of knowledge and the emergence of innovation.

Finally, based on this framework, it is possible to conclude that knowledge always tends to develop towards the idea of the ideal, and the direction of development of knowledge is determined by the difference between what is needed and what is currently possible (creating new knowledge or adapting what is currently known). The higher the difference between what is needed and what is possible, the higher the potential for converting knowledge into innovation, but the actual intensity of converting knowledge into innovation is defined by the limitations arising from the condition of society (profitability, legality, ethics) and compliance with the nature (sustainability). This means that the process of innovation consists of the generation of new knowledge (when needs are higher than possibilities) and/or the recombination of the existing knowledge (when possibilities are higher than needs) in a new way and its application in order to create a sustainable (profitable and compliant with nature) and value-adding solution (to a given problem).

\section{REFERENCES}

[1] Andreeva, T.; Kianto, A. (2011) Knowledge processes, knowledge-intensity and innovation: A moderated mediation analysis, Journal of Knowledge Management, 15, 6

[2] O’Brien, J., Remenyi, D., Keaney, A. (2004) Historiography - A Neglected Research Method in Business and Management Studies, Electronic Journal of Business Research Methods, Vol. 2, No 2, pp. 135-144

[3] Anand, N.; Gardner, H.K.; Morris, T. (2007), Knowledge-based innovation: Emergence and embedding of new practice areas in management consulting firms, Academy of Management Journal, Vol. 50, pp. 406-428

[4] Katila, R.; Chen, E.L. (2008) Effects of Search Timing on Innovation: The Value of Not Being in Sync with Rival, Administrative Science Quarterly, Vol.53, pp. 593-625,

[5] Nonaka, I. A. (1994). Dynamic theory or organizational knowledge creation. Organization Science, 5(1), 14-37

[6] Cohen, W.M.; Levinthal, D.A. (1990), Absorptive capacity: a new perspective on learning and innovation, Administrative Science Quarterly, Vol. 35 No. 1, pp. 128-52

[7] Henderson, R.M.; Clark, K. B. (1990). Architectural innovation: The reconfiguration of existing product technologies and the failure of established firms. Administrative Science Quarterly, 35(1), 9-22

[8] Rothwell, R. (1994), Towards the fifth-generation innovation process, International Marketing Review, Vol. 11 No. 1, pp. 7-31

[9] Abernathy, W.; Clark, K. B. (1985). Mapping the winds of creative destruction. Research Policy, 14, 3-22

[10] Chandy, R. K.; Tellis, G. J. (1998). Organizing for radical product innovation: The overlooked role of willingness to cannibalize. Journal of Marketing Research, 35(4)

[11] Mooij de, M.; Hofstede, G. (2002). Convergence and divergence in consumer behavior: implications for international retailing. Journal of Retailing, 78, 61-69

[12] Christensen, C. (1997) The Innovator's Dilemma, Harvard Business School Press, Boston

[13] Levinthal, D. (1998) The Slow Pace of Rapid Technological Change: Gradualism and Punctuation in Technological Change. Industrial and Corporate Change, Vol.7, pp. 217-247

[14] Katalinic, B.; Cosic, I.; Katic, V.; Tekic, Z. (2011) Engineer 2020 (in Serbian), Proceedings of XVII Conference Trendovi razvoja: "Europe 2020: Knowledge based society", pp. 13-21, ISBN 97886-7892-323-4, Novi Sad: Fakultet tehničkih nauka 